\title{
PENERAPAN MODEL PROBLEM SOLVING TERHADAP MOTIVASI DAN HASIL BELAJAR PESERTA DIDIK PADA MATERI STOIKIOMETRI
}

\section{Application Of Problem Solving Model For Motivation And Student Learning Results In Stoiciometry Materials}

\author{
Nita Saila Putri*, Leny, Mahdian \\ Program Studi Pendidikan Kimia FKIP Universitas Lambung Mangkurat, \\ Jl. Brigjend. H. Hasan Basry Banjarmasin 70123 Kalimantan Selatan Indonesia \\ *email: nitasailaputri15@gmail.com
}

\begin{abstract}
Abstrak. Penelitian ini bertujuan untuk mengetahui perbedaan motivasi dan hasil belajar peserta didik setelah diterapkan model problem solving pada materi stoikiometri di SMA PGRI 6 Banjarmasin. Metode yang digunakan adalah quasy experiment dengan desain non-equivalent pretest-posttest control group design dengan pemilihan sampel menggunakan purposive sampling. Populasi penelitian adalah kelas X MIPA, sedangkan sampel penelitian adalah kelas X MIPA 2 sebagai kelas eksperimen dan X MIPA 1 sebagai kelas kontrol. Pengumpulan data menggunakan teknik tes dan nontes. Teknik analisis data menggunakan analisis inferensial dan analisis deskriptif. Hasil penelitian menunjukkan bahwa (1) terdapat perbedaan motivasi dan hasil belajar yang signifikan antara peserta didik kelas eksperimen dan kelas kontrol, (2) hasil belajar kelas eksperimen lebih baik daripada kelas kontrol. Dari data tersebut, dapat disimpulkan terdapat perbedaan motivasi dan hasil belajar peserta didik antara kelas eksperimen dengan kelas kontrol di SMA PGRI 6 Banjarmasin.
\end{abstract}

Kata Kunci: Problem Solving, Motivasi, Stoikiometri

\begin{abstract}
This study aims to determine differences in motivation and student learning outcomes after applying the problem solving model to the stoichiometry material at SMA PGRI 6 Banjarmasin. The method used is a quasy experiment with a non-equivalent pretest-posttest control group design with sample selection using purposive sampling. The study population was class X MIPA, while the study sample was class X MIPA 2 as an experimental class and X MIPA 1 as a control class. Data collection using test and nontest techniques. Data analysis techniques using inferential analysis and descriptive analysis. The results showed that (1) there were significant differences in motivation and learning outcomes between experimental class and control class students, (2) experimental class learning outcomes were better than the control class. From these data, it can be concluded there are differences in motivation and student learning outcomes between the experimental class and the control class in SMA PGRI 6 Banjarmasin.
\end{abstract}

Keywords: Problem Solving, Motivation, Stoichiometry

\section{PENDAHULUAN}

Pendidikan adalah salah satu hal yang sangat penting bagi setiap individu guna memperbaiki kualitas hidup. Melalui proses pembelajaran di sekolah maka tujuan pendidikan dapat diwujudkan dan menghasilkan peserta didik yang bersemangat dalam menimba ilmu pengetahuan dan memiliki rasa ingin tahu yang tinggi. Salah satu indikator kualitas pembelajaran adalah adanya semangat ataupun motivasi belajar dari para pelajar. Peran aktif peserta didik sangat diharapkan dalam terciptanya pada

Copyright $\odot$ JCAE-Jurnal Tugas Akhir Mahasiswa, e-ISSN 2613-9782

Program Studi Pendidikan Kimia FKIP Universitas Lambung Mangkurat 
pembelajaran di Indonesia saat ini. Pendidikan saat ini bukan hanya difokuskan pada penguasaan materi, tetapi juga difokuskan pada proses yang dilalui untuk mencapai tujuan pembelajaran.

Hal yang perlu dicapai dalam kegiatan belajar mengajar adalah peserta didik harus memiliki kemampuan untuk berbuat sesuatu dengan menggunakan proses dan prinsip keilmuan yang telah dikuasai, learning to know (belajar untuk tahu) dan learning to do (belajar untuk berbuat) harus dicapai dalam kegiatan belajar mengajar (Hidayati, Leny, \& Iriani, 2018). Pada saat mengerjakan tugas peserta didik cenderung menunggu jawaban dari temannya dan hanya sebagian kecil yang berpartisipasi aktif dalam berdiskusi karena kurangnya keingintahuan terhadap materi pelajaran dan kurangnya rasa percaya diri dalam menyelesaikan tugas-tugas, hal ini menunjukkan rendahnya motivasi belajar (Herman \& Saadi, 2017).

Motivasi belajar peserta didik terhadap pelajaran IPA termasuk dalam kategori rendah, dapat dilihat dari hasil belajarnya baik dalam ranah pengetahuan ataupun ranah keterampilannya, dan indikator motivasi seperti attention, relevance, confidence dan satisfation. Dalam aktivitas belajar diperlukannya motivasi sebab seseorang yang tidak memiliki motivasi tidak akan mungkin melakukan aktivitas belajarnya (Apriani, 2015). Keller (2010) ARCS ialah aspek-aspek yang telah dikembangkan dan dapat digunakan untuk mengukur tingkat motivasi belajar.

Salah satu model pembelajaran yang digunakan pada kurikulum 2013 yaitu model pembelajaran problem solving yang digunakan untuk meningkatkan motivasi belajar peserta didik. Silayusa, Dantes, \& Suarni, (2015) menyatakan problem solving merupakan model pemecahan masalah yang menuntut peserta didik untuk dapat memecahkan berbagai masalah yang ada baik secara individual atau kelompok. Sejalan dengan penelitian Mukhlis (2017) bahwa penerapan model problem solving motivasi belajar peserta didik pada materi stoikiometri meningkat. Stoikiometri merupakan materi dasar dalam kimia yang harus bisa di pahami oleh peserta didik. Peserta didik harus mempunyai kemampuan analisa dan matematika yang baik agar dapat menyelesaikan soal- soal perhitungan dengan benar. Hal ini sesuai dengan beberapa penelitian diantaranya Bounjaoude \& Barakat (2003) dan Sirhan (2007). Adanya permasalahan dalam proses pembelajaran yang mengakibatkan hasil belajar peserta didik masih rendah.

Rendahnya hasil belajar dikarenakan di dalam proses pembelajaran interaksi guru dan peserta didik hanya berjalan satu arah. Guru yang sering menerapkan metode ceramah menyebabkan peserta didik cenderung hanya menerima apa yang diberikan dan mengakibatkan pembelajaran menjadi membosankan membuat suasana menjadi jenuh dalam mengikuti pembelajaran (Viani, Bahar, \& Elvinawati, 2017). Untuk itu perlu adanya perbaikan, guru harus mempersiapkan dan merencanakan segala sesuatu yang menunjang proses pembelajaran, memilih model yang sesuai agar dapat menimbulkan minat dan motivasi untuk belajar serta mengubah strategi belajar mengajar (Pristiwanto, 2016).

Berdasarkan pemaparan dilatar belakang betapa rendahnya motivasi dan hasil belajar peserta didik membuahkan keinginan untuk melakukan penelitian tentang penerapan model pembelajaran problem solving untuk mengetahui perbedaan motivasi dan hasil belajar peserta didik pada materi stoikiometri SMA PGRI 6 Banjarmasin.

\section{METODE PENELITIAN}

Metode dalam penelitiaan ini yaitu quasi experiment dengan menggunakan pola The Non equivalent Pretest-Posttest Control Group Design. Guru kimia di SMA PGRI 6 Banjarmasin menyarankan mengambil teknik purposive sampling. Penelitian 
ini dilakukan dari bulan April sampai Mei 2019 di SMA PGRI 6 Banjarmasin pada kedua kelas yang berbeda, yaitu kelas X MIPA 2 merupakan kelas eksperimen yang menggunakan model problem solving sebanyak 35 orang dan kelas X MIPA 1 sebagai kelas kontrol yang menggunakan model DI sebanyak 35 orang. Kegiatan pengajaran dilakukan sebanyak dua pertemuan pada setiap kelas. Instrumen yang digunakan pada penelitian ini yaitu angket motivasi yang berisi 36 pernyataan yang berhubungan dengan motivasi ARCS dan tes berupa pilihan ganda pada materi stoikiometri. Penilaian pada penelitian dengan teknik tes yang dilaksanakan pada pertemuan awal (pre-test) dan pertemuan akhir (post-test), dengan analisis deskriptif dan inferensial. Perangkat penelitian berupa RPP, LKPD dan lembar penilaian.

\section{HASIL PENELITIAN DAN PEMBAHASAN}

A. Data analisis perbedaan motivasi belajar

Persentase motivasi peserta didik masing-masing kelas terdapat pada Gambar 1.

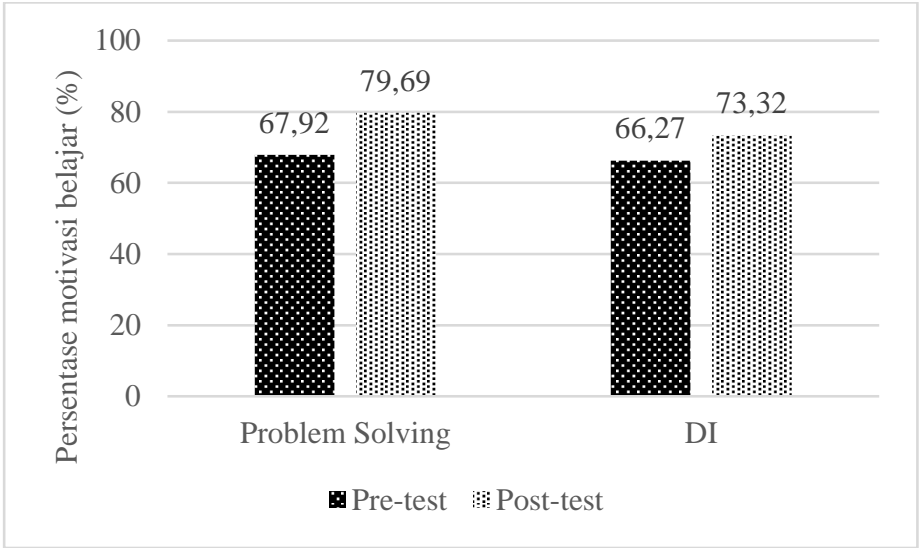

Gambar 1. Presentase motivasi belajar

Motivasi belajar untuk jawaban pre-test di kelas problem solving lebih banyak dari pada kelas DI. Kedua kelas berada pada kualifikasi cukup. Setelah diberikan perlakuan, persentase hasil post- test motivasi belajar peserta didik pada kelas problem solving yaitu 79,69\% berada pada kualifikasi tinggi, sementara kelas DI yaitu $73,32 \%$ berada pada kualifikasi tinggi. Sejalan dengan penelitian Santoso, Budiyono, \& Subanti (2014) menyatakan bahwa menggunakan model pembelajaran dengan metode ceramah, dapat membuat proses belajar mengajar cenderung membosankan, peserta didik malas belajar, dan menjadi pasif.

Sukma, Komariyah, \& Syam (2016) indikator motivasi belajar ARCS yaitu attention, relevance, convidence, dan satisfaction. Berdasarkan data tersebut jika motivasi belajar ditinjau dari setiap komponen dan dinyatakan dalam bentuk presentase rata-rata, maka hasilnya dapat dilihat pada Gambar 2. 


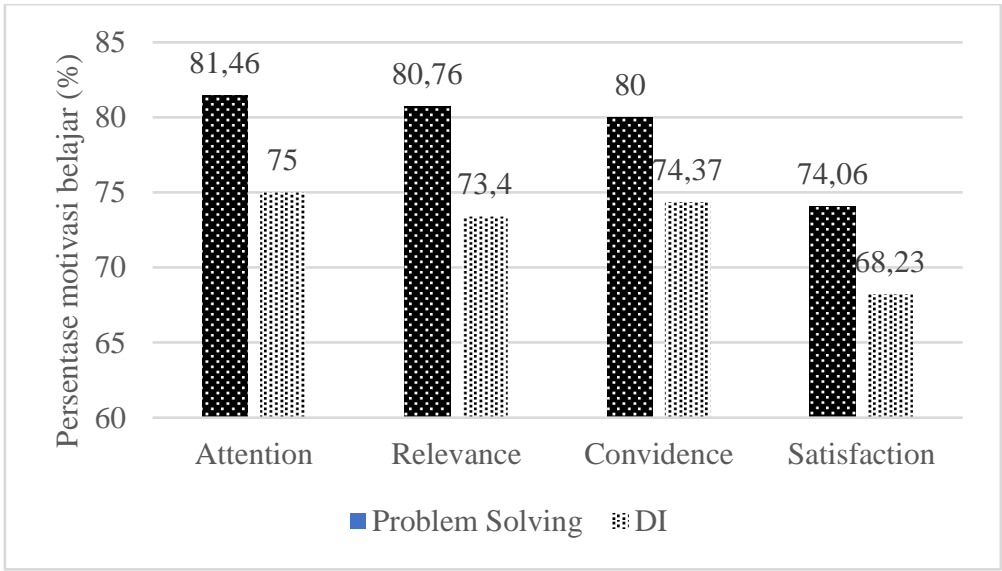

Gambar 2. Persentase rata-rata motivasi belajar tiap komponen

Gambar 2 menunjukkan bahwa motivasi belajar komponen attention pada kelas problem solving lebih tinggi daripada kelas DI yaitu $81,46 \%$ hal ini dikarenakan penerapan model pembelajaran problem solving menarik perhatian peserta didik pada tahapan memahami masalah dan merencanakan penyelesaian. Tahapan memahami salah dapat menarik perhatian dimana guru menunjukkan permasalahan yang berhubungan dengan materi stoikiometri dengan memanfaatkan media pembelajaran yang dapat merangsang ketertarikan sehingga mereka termotivasi untuk mengikuti pembelajaran. Sejalan dengan pendapat Falahudin (2014) proses belajar mengajar dengan memanfaatkan penggunaan media pembelajaran dapat membangkitkan minat, membangkitkan motivasi dan membawa pengaruh psikologis terhadap pelajar.

Tahap merencanakan penyelesaian juga dapat menarik perhatian pelajar dimana guru membimbing peserta didik untuk mengidentifikasi masalah dengan rinci dan teliti dalam merencanakan langkah-langkah penyelesaian masalah. Komponen relevance pada kelas problem solving yaitu 80,76 lebih tinggi daripada kelas DI. Pada kelas problem solving komponen relevance dapat dilakukan pada tahapan melakukan penyelesaian sesuai rencana. Komponen convidence yaitu komponen yang dapat membangun pemikiran positif untuk menyelesaikan tugasnya terkait dalam pembelajaran. Terakhir komponen satisfaction yaitu yang berhubungan dengan pemberian penghargaan, rata-rata persentase untuk kelas eksperimen yaitu 74,06\% dan dapat dilakukan pada tahapan memeriksa kembali. Dengan demikian satisfaction (kepuasan) peserta didik meningkat dengan memberikan pengahargaan lain berupa nilai tambahan kepada pelajar, sehingga peserta didik merasakan kepuasan atas award yang diberikan. Di dukung oleh Yosua (2013) menyatakan bahwa dalam mencapai suatu tujuan akan menghasilkan kepuasan.

Motivasi belajar post-test kelas DI lebih rendah daripada kelas problem solving. Setelah dhitung menggunakan uji-t ditemukan perbedaan yang signifikan antara kelas problem solving dengan kelas DI. Perbedaan ini karena adanya pengaruh dari pembelajaran problem solving pada kelas eksperimen yang mengharuskan peserta didik memecahkan masalah sendiri. Hal ini dapat dilihat pada uji-t dan nilai $\mathrm{N}$-gain kedua kelas yang ada pada Tabel 1 dan Tabel 2. 
Tabel 1 Uji-t data pre-tes dan post-test motivasi belajar

\begin{tabular}{lccccccc}
\hline Hasil & Kelas & Db & $\mathbf{X}$ & SD $^{\mathbf{2}}$ & thitung & $\begin{array}{c}\text { ttabel } \\
(\boldsymbol{\alpha}=\mathbf{0 , 0 5})\end{array}$ & Kesimpulan \\
\hline $\begin{array}{l}\text { Pre- } \\
\text { test }\end{array}$ & $\begin{array}{c}\text { Problem } \\
\text { solving } \\
\text { DI }\end{array}$ & 31 & 67,92 & 9,56 & 1,92 & 1,99 & $\begin{array}{c}\text { Tidak } \\
\text { signifikan }\end{array}$ \\
\hline $\begin{array}{l}\text { Post }- \\
\text { test }\end{array}$ & $\begin{array}{c}\text { Problem } \\
\text { solving } \\
\text { DI }\end{array}$ & 31 & 79,69 & 20,99 & 5,17 & 1,99 & Signifikan \\
& & 73,32 & 29,98 & & & \\
\hline
\end{tabular}

Tabel 2 Interprestasi N-gain motivasi belajar

\begin{tabular}{ccc}
\hline Kelas & Rata-rata $\boldsymbol{N}$-gain & Kualifikasi \\
\hline Problem solving & 0,36 & Sedang \\
DI & 0,20 & Rendah \\
\hline
\end{tabular}

Berdasarkan Tabel 1 terlihat bahwa terdapat perbedaan yang signifikan antara kelas problem solving dan kelas DI setelah diberi perlakuan. Tabel 2 menunjukkan kelas problem solving mengalami peningkatan motivasi belajar karena menerapkan model problem solving. Hal ini sesuai dengan penelitian Fajria, Rahmatan , \& Halim (2017) penerapan model problem solving dapat mengatasi permasalahan yang diberikan oleh guru dan peserta didik dituntut untuk menemukan sendiri jawaban dari permasalahan tersebut.

\section{B. Data analisis perbedaan hasil belajar}

Data hasil belajar pengetahuan diperoleh dari pre-test dan post-test kelas problem solving dan kelas DI terdapat pada Tabel 3.

Tabel 3 Nilai hasil belajar pengetahuan

\begin{tabular}{ccccc}
\hline \multirow{2}{*}{ Nilai } & \multicolumn{2}{c}{ Problem solving } & \multicolumn{2}{c}{ DI } \\
& Pre-test & Post-test & Pre-test & Post-test \\
\hline Terendah & 20 & 60 & 10 & 50 \\
Tertinggi & 80 & 100 & 80 & 90 \\
Rata-Rata & 50,94 & 81,56 & 47,19 & 72,19 \\
\hline
\end{tabular}

Berdasarkan Tabel 3 diketahui bahwa hasil belajar pengetahuan baik kelas problem solving dan kelas DI sebelum diberikan perlakuan seluruhnya berada pada kualifikasi kurang baik. Setelah diberikan perlakuan, hasil belajar pengetahuan kelas problem solving mendapatkan nilai sangat baik sebesar 81,56 sedangkan kelas DI 72,19 yang menunjukkan bahwa hasil belajar pengetahuannya meningkat. Hal ini dapat dilihat pada uji-t dan nilai $\mathrm{N}$-gain kedua kelas yang ada pada Tabel 4 dan Tabel 5.

Tabel 4 Uji-t data hasil belajar pengetahuan

\begin{tabular}{cccccccc}
\hline Hasil & Kelas & Db & $\mathbf{X}$ & $\mathbf{S D}^{2}$ & thitung & $\begin{array}{c}\text { ttabel } \\
(\boldsymbol{\alpha}=\mathbf{0 , 0 5})\end{array}$ & Kesimpulan \\
\hline \multirow{2}{*}{ Pre-test } & $\begin{array}{c}\text { Problem } \\
\text { solving } \\
\text { DI }\end{array}$ & 31 & 50,94 & 331,35 & 0,84 & 1,99 & $\begin{array}{c}\text { Tidak } \\
\text { signifikan }\end{array}$ \\
& $\begin{array}{c}\text { Problem } \\
\text { Post-test }\end{array}$ & & 47,19 & 291,83 & & & \\
& solving & 31 & 81,56 & 136,19 & 3,29 & 1,99 & Signifikan \\
& DI & & 72,19 & 114,42 & & & \\
\hline
\end{tabular}


Tabel 5 Interprestasi N-gain hasil belajar pengetahuan

\begin{tabular}{ccc}
\hline Kelas & Rata-rata $N$-gain & Kualifikasi \\
\hline Problem solving & 0,63 & Sedang \\
DI & 0,40 & Rendah \\
\hline
\end{tabular}

Berdasarkan Tabel 4 terlihat adanya perbedaan antara hasil belajar pengetahuan kelas problem solving dengan kelas DI setelah diberi perlakuan. Pada Tabel 5 juga terlihat bahwa nilai $\mathrm{N}$ - gain yang lebih tinggi yaitu pada kelas problem solving dibandingkan dengan kelas DI. Sehingga menunjukkan peningkatan hasil belajar pengetahuan dengan menerapkan model problem solving. Adapun nilai ratarata per-indikator hasil post-test dapat dilihat pada Gambar 3.

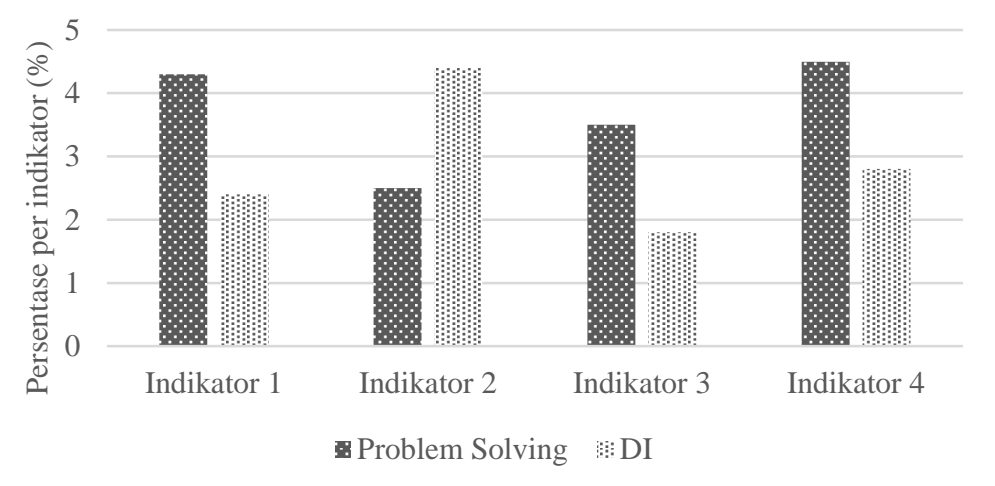

Gambar 3. Nilai post-test hasil belajar pengetahuan per indikator

Indikator 1 menentukan Ar dan Mr. Persentase nilai yang menjawab benar adalah untuk kelas problem solving dan kelas DI sama yaitu 92,19\% dan termasuk kategori sangat baik. Saol pada indikator ini terdiri dari 2 soal, dimana pada saat proses pembelajaran peserta didik telah memahami bagaimana menentukan $\mathrm{Ar}$ dan $\mathrm{Mr}$ hanya cukup mengingat konsep yang telah dipelajari sehingga hampir semua peserta didik bisa menjawab soal ini dengan baik.

Pada indikator 2 mengenai menentukan keterkaitan antara jumlah mol dengan jumlah partikel, massa dan volume zat dengan hasil persentase kelas problem solving $79,17 \%$ termasuk dalam kategori cukup baik dan untuk kelas DI 64,58\% termasuk kategori kurang baik karena peserta didik masih belum dapat menentukan mol dari bilangan Avogadro, hal itu terjadi karena peserta didik belum memahami dengan tepat terutama dalam menentukan mol dan belum mampu membolak balikan rumus. Soal pada indikator ini terdiri 3 soal.

Pada indikator 3 yaitu menentukan rumus empiris dan rumus molekul suatu senyawa. Soal dari indikator ini terdiri dari 2 soal dengan hasil persentase untuk kelas problem solving $68,75 \%$ dan kelas DI 57,81\% dan keduanya termasuk kategori kurang baik. Hal ini menandakan bahwa peserta didik kurang sepenuhnya paham mengenai rumus empiris dan rumus molekul.

Pada indikator 4 yaitu menhitung rumus empiris dan rumus molekul. Pada indikator ini terdiri 3 soal dengan hasil presentase $85,42 \%$ untuk kelas problem solving termasuk kategori baik dan 76,04\% untuk kelas DI dan termasuk kategori cukup baik. Tingginya rata-rata pada indikator 4 disebabkan para pelajar sudah mulai terbiasa dengan soal-soal perhitungan dan sudah mulai dibimbing untuk melakukan perhitungan kimia dalam suatu persamaan reaksi, sehingga siswa dapat menjawab soal yang diberikan. 
Perbedaan pencapaian hasil ini disebabkan pembelajaran pada kelas yang menerapkan model problem solving. Sejalan dengan penelitian Dewi, Rudibyani, \& Efkar (2018) dan Khairani \& Safitri (2017) menyatakan bahwa problem solving efektif karena pengetahuan dasar yang digunakan dalam belajar ialah teori dan praktik. Hasil belajar ranah sikap baik di kelas problem solving maupun kelas DI terdapat Tabel 6.

Tabel 6 Nilai rata-rata ranah sikap

\begin{tabular}{cccc}
\hline No & Sikap & $\begin{array}{c}\text { Rata-rata \% } \\
\text { Problem solving }\end{array}$ & Rata-rata \% DI \\
\hline 1 & Rasa ingin tahu & 89,45 & 79,69 \\
2 & Kerja sama & 89,45 & 73,83 \\
3 & Bertanggung jawab & 90,63 & 79,69 \\
& Rata-Rata Total (\%) & 89,84 & 77,73 \\
\hline & Kualifikasi & Sangat baik & Baik \\
\hline
\end{tabular}

Berdasarkan Tabel 6 kelas problem solving mempunyai rata-rata persentase ranah sikap rasa ingin tahu yang berbeda jika dibandingkan dengan kelas DI. Perbedaan ini disebabkan pada kelas problem solving terdapat tahapan memahami masalah sehingga melatih kemampuan pemecahan masalah sehingga rasa ingin tahu dapat meningkat. Sejalan dengan penelitian Rahmawan, Utomo, \& Sukardjo (2016) bahwa menerapkan model problem solving pada materi stoikiometri dapat meningkatkan rasa ingin tahu.

Rata-rata persentase ranah sikap bertanggung jawab kelas eksperimen 90,63\% sedangkan kelas kontrol sebesar 79,69\%, selisih dari rata-rata persentase kedua kelas adalah $10,94 \%$. Hal ini disebabkan peserta didik mampu berpartisipasi secara aktif dalam kelompoknya dan ketika presentasi hasil diskusi masing-masing anggota kelompok juga berusaha mempertahankan pendapatnya terlebih dahulu.

Rata-rata persentase ranah sikap kerja sama kelas problem solving memiliki nilai lebih tinggi dari pada kelas DI. Hal ini karena selama pembelajaran peserta didik di kelas problem solving terlihat aktif berdiskusi dan menunjukkan sikap kolaboratif dengan memastikan pemahaman anggota kelompok terhadap tugas yang diberikan. Kemudian dari rata-rata keseluruhan aspek hasil belajar sikap yang dinilai, didapatkan rata-rata total kelas problem solving termasuk dalam kualifikasi sangat baik dan kelas DI termasuk dalam kualifikasi baik.

Data penilaian keterampilan peserta didik baik di kelas problem solving ataupun kelas DI dapat dilihat pada Tabel 7 berikut.

Tabel 7 Nilai rata-rata ranah keterampilan

\begin{tabular}{clcc}
\hline No. & \multicolumn{1}{c}{ Sikap } & $\begin{array}{c}\text { Rata-rata (\%) } \\
\text { Problem Solving }\end{array}$ & Rata-rata (\%) DI \\
\hline 1. & Membuat pertanyaan & 69,14 & 59,77 \\
2. & Komunikasi lisan & 80,86 & 66,02 \\
3. & Menjawab pertanyaan & 87,50 & 75,00 \\
& Rata-rata total & 79,17 & 66,93 \\
\hline & Kualifikasi & Terampil & Cukup Terampil
\end{tabular}

Berdasarkan Tabel 7 persentase ranah keterampilan membuat pertanyaan mengalami peningkatan dalam 2 pertemuan baik itu kelas problem solving atau kelas DI namun kelas problem solving lebih tinggi daripada kelas DI hal ini disebabkan oleh peserta didik di kelas DI kurang antusias dalam mengikuti pembelajaran.

Rata-rata persentase ranah keterampilan komunikasi lisan meningkat pada tiap pertemuandi kelas problem solving sebesar 80,86\% dan kelas DI 66,02\% hal ini di 
sebabkan dengan seiring dengan peningkatan rasa ingin tahu peserta didik. Rata-rata persentase ranah keterampilan menjawab pertanyaan di kelas problem solving nilai rata-rata persentase lebih tinggi yaitu $87,50 \%$ termasuk kategori sangat terampil sedangakan di kelas DI 75,00\% termasuk kategori terampil. Hal ini disebabkan peserta didik di kelas DI masih kurang berani dalam menyampaikan pendapatnya. Kemudian dari rata-rata keseluruhan ranah keterampilan yang dinilai, didapatkan ratarata total kelas problem solving sebesar $79,17 \%$ yang termasuk dalam kualifikasinya terampil dan rata-rata total kelas DI sebesar $66,93 \%$ yaitu termasuk dalam kualifikasi cukup terampil.

\section{SIMPULAN}

Penelitian ini dapat disimpulkan bahwa ditemukan adanya perbedaan yang signifikan pada motivasi dan hasil belajar peserta didik yang menerapkan model pembelajaran problem solving dan yang menerapkan model pembelajaran DI pada materi stoikiometri SMA PGRI 6 Banjarmasin. Diharapkan model pembelajaran problem solving dapat dijadikan pilihan dalam kegiatan pembelajaran untuk meningkatkan motivasi dan hasil belajar serta dapat diterapkan dengan materi yang berbeda serta merancang alokasi dengan baik agar proses pembelajaran dapat berjalan lebih efektif.

\section{DAFTAR RUJUKAN}

Apriani, N. D. (2015). Upaya Meningkatkan Motivasi dan Prestasi Belajar Mahasiswa Dengan Pembelajaran Kooperatif Tipe Thingking Aloud Pairs Problem Solving Pada Mata Kuliah Aljabar Linear. Jurnal Beta, 142-152.

Bounjaoude, S., \& Barakat, H. (2003). Students Problem Solving Strategies in Stoichiometry and their Prelationships to Conceptual Understanding and Learning Aprroaches. Electronic Journal of Science Education.

Dewi, A. A., Rudibyani, R. B., \& Efkar, T. (2018). Efektifitas Problem Solving untuk Meningkatkan Motivasi Belajar dan penguasaan Konsep Materi Elektrolit/Non Elektrolit. Science Education.

Fajria, F., Rahmatan , H., \& Halim, A. (2017). dampak Model Pembelajaran Problem Solving Terhadap Motivasi dan Hasil Belajar Peserta Didik di SMP. Jurnal Pendidikan Sains Indonesia, 86-93.

Falahudin, I. (2014). Pemanfaatan Media dalam Pembelajaran. Jurnal Lingkar Widyaiswara, 104- 117.

Herman, \& Saadi, P. (2017). Penerapan Model Problem Solving Melalui Pendekatan Kontekstual Pada Materi Hidrolisis Garam Dalam Meningkatkan Motivasi Belajar dan Hasil Belajar Siswa. QUANTUM, Jurnal Inovasi Pendidikan Sains, 52-62.

Hidayati, N., Leny, \& Iriani, R. (2018). Pengaruh Model Pembelajaran Inquiri Based Learning Dengan Pendekatan Flipped Classroom Terhadap Self Efficancy dan Hasil Belajar Kesetimbangan Ion Dalam Larutan Garam. Prosiding Seminar Nasional Pendidikan Kimia, 99-107.

Keller, J. M. (2010). Motivation Design for Learning and Performance : the ARCS Model Approach.

You York: Springer.

Khairani, I., \& Safitri, R. (2017). Penerapan Metode Pembelajaran Problem Solving Untuk Meningkatkan Hasil belajar Peserta Didik pada Materi Usaha dan Energi di MAN Rukoh Aceh. Jurnal Pendidikan Sains Indonesia, 32-41.

Muklhis. (2017). Pembelajaran Model Problem Solving Materi Stoikiometri Pada Mata Kuliah Kimia Dasar 1 Untuk Meningkatkan Motivasi, Keterampilan 
Genetik Sains dan pemahaman Konsep Mahasiswa. Jurnal IPA dan Pembelajaran IPA (JIPI).

Pristiwanto. (2016). Penerapan Metode Pemecahan Masalah (Problem Solving) Untuk Meningkatkan Pemahaman Siswa tentang Komponen Peta. Wahana Pedagogika, 127-134.

Rahmawan, A. A., Utomo, S. B., \& Sukardjo, J. S. (2016). Penerapan Model Pembelajaran Problem Solving Untuk Meningkatkan Rasa Ingin Tahu dan prestasi Belajar Kimia Pada Materi Hukum Dasar dan Perhitungan Kimia Siswa kelas X-TP 3 SMK Muhammadiyah 2 Sragen Tahun pelajaran 2015/2016. Jurnal Pendidikan Kimia.

Santoso, B., Budiyono, \& Subanti, S. (2014). Eksperimentasi Model Pembelajaran Team Games Tournament (TGT) dan Jigsaw Dengan Pendekatan Matematika Realistik Ditinjau Dari Kecemasan Menghadapi Tes Siswa Kelas VII SMP Kabupaten Brebes Tahun Pelajaran 2012/2013. Jurnal ElektronikPembelajaran Matematika, 88-98.

Silayusa, P. N., Dantes, N., \& Suarni, K. N. (2015). Pengaruh Metode Pembelajaran Problem Solving Berbantuan Media Audio Terhadap Motivasi Belajar dan Prestasi Belajar IPS Siswa LB di SLB A Negeri Semarang. E-journal Program Pascasarjana Universitas Pendidikan ganesha, 1-11.

Sirhan, G. (2007). Learning Difficulties in Chemistry: An Overview. The Journal of Turkish Science Education, 2-20.

Sukma, Komariyah, L., \& Syam, M. (2016). Pengaruh Model Pembelajaran Inquiri Terbimbing (Guided Inquiry) dan Motivasi Terhadap Hasil Belajar Fisika Siswa . Jurnal UNEJ, 59-63.

Viani, D. S., Bahar, A., \& Elvinawati. (2017). Perbandingan Hasil Belajar Siswa Menggunakan Media Chempoly Game dan Tournamen Question Cards. Jurnal Pendidikan dan Ilmu Kimia, 55-59.

Yosua, A. W. (2013). Pengaruh Perhatian, Relevansi, Kepercayaan Diri, dan Kepuasan Terhadap Motivasi Belajar Mahasiswa Fakultas Ekonomi Jurusan Manajemen Universitas Riau di Pekanbaru. Jurnal Motivasi Belajar, 1-15. 